\title{
A Juventude Rural do Assentamento Florestan Fernandes no Município de Florestópolis (PR)
}

\author{
Fernando Luis Martins Costa $^{1}$ e Ricardo Ralisch ${ }^{2}$
}

\begin{abstract}
Resumo: A possibilidade de uma crise na agricultura familiar referente à sucessão do empreendimento se mostra preocupante na medida em que alguns filhos abandonam a propriedade por não poder ou não querer exercer a profissão de agricultor. Esta é uma situação que pode comprometer a viabilidade socioeconômica de assentamentos rurais da reforma agrária. Neste sentido, o objetivo deste estudo de caso foi conhecer os anseios, as perspectivas de futuro e a realidade em que vivem os jovens rurais moradores do assentamento Florestan Fernandes, localizado no município de Florestópolis (PR), uma vez que eles poderiam ser os protagonistas na continuidade de exploração dos lotes conquistados. Concluiu-se que a maioria dos jovens tem grande interesse em continuar vivendo e trabalhando nos lotes com os pais, mas a limitação da renda obtida pela família nas atividades agropecuárias e a falta de renda própria levam estes jovens a optar por sair da propriedade, em busca de novas oportunidades.
\end{abstract}

Palavras-chaves: Juventude rural, sucessão familiar, assentamento rural, política agrícola.

Abstract: The possibility of a crisis in family farming referring on the succession of the company is concerning when some children leave the property because they are not able or do not want to be a farmer. This is a situation that could affect the socioeconomic viability of rural settlements of Agrarian Reform. Therefore, the objective of this case study was to know desires, future perspectives and the reality experienced by the young residents of the rural settlement Florestan Fernandes, located in Florestópolis (PR), since these young actors could continue to use gained batches. It was concluded that the majority of these young people have great interest in continue living and working in the batches with their parents, but the limitation of the family earnings in agricultural activities and the lack of their own income force young people to choose leaving the property to seek new opportunities.

Key-words: Rural youth, family succession, rural settlement, agricultural policy.

\section{Classificação JEL: Q15.}

1 Engenheiro agrônomo do Emater Florestópolis (PR). E-mail: fernandocosta@emater.pr.gov.br

2 Professor do programa de Pós-graduação em Agronomia da UEL. E-mail: ralisch@uel.br 


\section{Introdução}

A agricultura familiar é responsável por garantir boa parte da segurança e soberania alimentar do País, sendo considerada como a principal fornecedora de alimentos para o mercado interno (BRASIL, 2006).

Destaca-se também como importante potencial na criação de condições e oportunidades de trabalho e sobrevivência, por meio de diversificados sistemas de produção, que contribuem principalmente para o desenvolvimento de pequenos municípios (LOURENZANI, 2006).

A agricultura familiar no Brasil passou a ser reconhecida de fato a partir de 2006 através da Lei n. 11.326, que estabeleceu as diretrizes para a formulação da Política Nacional da Agricultura Familiar e Empreendimentos Familiares Rurais (BRASIL, 2006). A partir daí, foram fixadas políticas públicas específicas para esta classe, mas que não contemplaram as necessidades dos jovens. Assim, apesar de as estatísticas apresentarem a agricultura familiar como fundamental para o crescimento econômico de algumas regiões, tais dados não dão conta de explicar os processos de migração e êxodo rural, principalmente por parte da juventude (BADALOTTI et al., 2007).
Conforme Abramovay et al. (1998), este esvaziamento do campo é uma das maiores ameaças para o desenvolvimento rural. A ideia de que os filhos reproduzem os papéis dos pais cada vez mais se distancia da realidade, o que prejudica o processo de sucessão familiar da propriedade.

Este êxodo da juventude promove um envelhecimento do meio rural, agravado ainda pelo fato de que a maior parte dos emigrantes rurais são moças, o que, além de tornar o meio rural envelhecido, também caminha para um processo de masculinização do campo. A situação das mulheres é mais delicada e deriva da desvalorização das atividades realizadas por elas, por serem considerados trabalhos mais leves, percebidos mais como uma ajuda dentro da propriedade, e que acaba distorcendo verdadeiramente as múltiplas jornadas do trabalho da mulher na área rural (CAMARANO e ABRAMOVAY, 1997; PAULILO, 2004). Estas situações provocam um desinteresse por parte das moças na continuidade da vida no campo, que acabam atraídas pelos centros urbanos em busca de trabalho remunerado e reconhecimento, bem como uma melhoria de vida. Essa predominância de mulheres migrando para a cidade não está ligada às condições favoráveis para esse gênero no mercado de trabalho urbano, 
mas, sim, à desvalorização do seu trabalho no campo e à falta de perspectivas que elas vivenciam (ABRAMOVAY et al., 1998).

Esse desejo migratório dos jovens, em grande parte, é justificado por uma visão relativamente negativa da atividade agrícola e dos benefícios que ela proporciona, além das características referentes à limitação do tamanho da área de terra ou problemas existentes na transferência dos estabelecimentos agrícolas familiares à nova geração (BRUMER, 2006).

Por outro lado, Bamat e Ieno Neto (1998), em pesquisa a assentamentos rurais no estado da Paraíba, mostram que muitos jovens rurais gostariam de dar continuidade aos lotes que seus pais receberam, mas com a possibilidade de acessarem as facilidades e conforto, como educação, transporte, lazer, utilização de máquinas para o trabalho nas propriedades, celular, televisão, computador e outros benefícios até então privilégios do meio urbano. Estas reivindicações demandadas pelos jovens abrem possibilidades para que eles participem do desenvolvimento da comunidade.

Despertados para esta situação, alguns pesquisadores estão discutindo os novos desafios da juventude rural no sentido de buscar explicações e dar sugestões de estratégias que impliquem na continuidade da agricultura familiar. Abramo e Branco (2005) comentam que o interesse dos pesquisadores brasileiros sobre o universo social e cultural dos jovens rurais é recente, sendo a bibliografia disponível bastante limitada, diferente do que ocorre com a população jovem dos grandes centros urbanos, que tem atraído a atenção de um número muito maior de estudiosos.

Segundo Castro (2009), algumas entidades sociais também iniciaram projetos e programas para a juventude rural, principalmente a partir de 2001, tendo como destaque a Fetaep (Programa Jovem Saber), Faep (Jovem aprendiz), Cedejor (Centro de desenvolvimento do jovem rural), Contag (Comissão nacional de jovens trabalhadores e trabalhadoras rurais), Fetraf (Coletivos de juventude), MAB (Coletivo nacional), MST (Coletivo nacional da juventude), Via
Campesina Brasil (Coletivo nacional de juventude) e Emater de alguns estados, além de outras organizações que já realizam projetos mais antigos, como PJ e PJR (Pastoral da juventude rural), Arcafar (Associação regional das casas familiares rurais), Pronera (Programa nacional de educação na reforma agrária). Estes projetos e programas específicos para a juventude revelam muito sobre como esses jovens se percebem. Se por um lado reforçam questões consideradas específicas, como acesso à educação e a terra, por outro, constroem transformações sociais da própria realidade do campo e da sociedade brasileira.

Durston (1999) chamava a atenção para o tema juventude rural, sobre o qual observava que, apesar dos esforços de algumas instituições, não se tinha ainda a dedicação e a importância merecida entre aqueles que possuíam a responsabilidade na execução de programas e projetos de desenvolvimento rural. Invisível para a maioria das pesquisas e projetos voltados para o mundo rural, essa categoria imprecisa, variável, construída socialmente, vem, aos poucos, chamando a atenção de analistas das questões rurais.

Reuben (1990) argumenta que a invisibilidade é um dos principais fatores que inibem o desenvolvimento das potencialidades dos jovens, o que os impede de contribuir para o desenvolvimento rural sustentável. A primeira barreira é de ordem cultural e está associada aos conflitos dos jovens na família. O autor afirma que o jovem não consegue ser ouvido em seu ambiente familiar. A estrutura patriarcal, ainda existente na maioria das áreas rurais, limita o acesso dos jovens a manifestações e até mesmo na tomada de decisões.

O êxodo do jovem rural não pode ameaçar a ainda incipiente reforma agrária e se transformar em um jogo de soma zero, onde os assentamentos realizados de um lado podem não compensar os "desassentamentos" sofridos do outro (PEREIRA, 2009).

Pesquisas realizadas por Carneiro (2005) identificaram que os temas que os jovens rurais mais se interessam são: educação, emprego, cultura e lazer. 
A importância da educação como forma de se conseguir uma profissão menos desgastante e melhor remunerada do que a de agricultor foi demonstrada em pesquisas, por Silvestro et al. (2001), como o principal objetivo, não só pelos jovens, mas também por seus pais, de verem seus filhos em outras ocupações menos trabalhosas do que a de produtor rural. Desta maneira, a formação é vista no meio rural como uma alternativa para saírem do campo.

A velha tradição, sobre a qual geralmente o filho mais novo ficava na propriedade, começa a desaparecer, permanecendo quem possui menos vocação para o estudo. Assim, cria-se um círculo vicioso em que permanecer no meio rural associa-se a uma espécie de incapacidade pessoal de trilhar o suposto caminho do sucesso que, neste caso, consiste sobre o fato de ter conseguido migrar, e quem não investe no conhecimento será identificado como aquele que permanecerá no reduto dos velhos, dos aposentados e daqueles que "não conseguem sair" (CARNEIRO, 2005).

Atividades de socialização como cultura e lazer podem contribuir para a valorização do meio rural, mas possuem pouco espaço nas comunidades. Por isso, os jovens rurais acabam encontrando mais alternativas nas cidades. Castro (1998) afirma que as fronteiras rurais e urbanas são constantemente diluídas no cotidiano. Morando em áreas rurais e transitando por áreas urbanas, os jovens vivenciam diferentes redes sociais e práticas culturais.

Discutir a realidade da juventude rural hoje implica um olhar mais atento às suas lutas, sonhos e angústias. Significa pensar nos problemas e nas perspectivas possíveis para essa parcela de jovens que se vê na fronteira entre manter-se no campo ou migrar para os centros urbanos à procura de melhores condições de vida. No entanto, se ficar no campo significa encarar uma dura realidade de privações e de falta de perspectivas, migrar para as cidades traz outras sérias consequências, como enfrentar o crescente desemprego, a pobreza e a violência (CAMPOLIN, 2005).

Conhecendo-se as tendências migratórias, as visões e perspectivas dos jovens quanto à ativi- dade agrícola, surge a necessidade de inverter a questão e procurar pesquisar aspectos positivos que favoreçam sua permanência. Desse modo, tornam-se indispensáveis os estudos que analisam o modo de vida, as relações sociais, as condições estruturais, as oportunidades de lazer e acesso a atividades agrícolas e não agrícolas, para jovens de ambos os sexos (BRUMER, 2004).

Refletir sobre a população jovem dos assentamentos revela uma preocupação referente ao desenvolvimento e ao futuro da agricultura familiar, podendo ser estendida para uma discussão sobre a viabilidade da reforma agrária.

Neste contexto, o objetivo deste trabalho é conhecer a realidade em que vivem os jovens rurais do assentamento Florestan Fernandes, seus anseios e perspectivas sobre o seu projeto de vida.

\section{Materiais e métodos}

O presente estudo foi realizado no Assentamento Florestan Fernandes sobre coordenadas geográficas $22^{\circ}{ }^{\circ} 2^{\prime} 46^{\prime \prime} \mathrm{S}$ e $51^{\circ} 27^{\prime} 09^{\prime \prime} \mathrm{O}$, localizado no município de Florestópolis, região norte do estado do Paraná. A propriedade deste assentamento foi adquirida por meio do processo de obtenção de terras por compra e venda baseado no Art. $1^{\text {o }}$ do Decreto 433 (ROCHA, 2009), sendo negociada diretamente com o Incra (Instituto Nacional de Colonização e Reforma Agrária) e sem maiores conflitos com o MST (Movimento dos Trabalhadores Sem-terra) e o proprietário, uma vez que não ocorreu ocupação das terras para desapropriação. Até o final da década de 1970, esta propriedade desenvolvia a cafeicultura, que depois deu lugar às pastagens para a atividade de bovinocultura de corte e para a produção de cana-de-açúcar. Um grupo de integrantes do MST foi selecionado para fazer parte deste novo assentamento. Assim, em dezembro de 1998, o Incra oficializou o Assentamento Florestan Fernandes, com 29 famílias (INCRA, 2008). Ocorreram diferentes trajetórias econômicas e sociais desde o período de implantação do assentamento. As primeiras atividades econômi- 
cas nos lotes foram as culturas da soja, milho e mandioca durante o verão e a cultura do feijão no inverno. No correr dos anos, algumas famílias de assentados foram substituídas por outras e as atividades agropecuárias como fruticultura, bovinocultura de leite e sericicultura foram ganhando importância, tornando-se as principais atividades econômicas desenvolvidas. Da mesma forma, questões sociais evoluíram neste período, constatando-se maior integração à sociedade local, maior acesso aos serviços públicos municipais e fortalecimento político, entre outros (EMATER, 2008). Atualmente, a população do Assentamento Florestan Fernandes é constituída por 112 pessoas distribuídas nas 29 famílias.

Para esta pesquisa foi realizado inicialmente um diagnóstico utilizando-se o questionário para tipologia desenvolvido pelo Programa Redes de Referência (CARVALHO et al., 2001), conforme Anexo I, para conhecimento da realidade socioeconômica da comunidade, realizando-se visitas às propriedades e entrevistas com os titulares e cônjuges de todas as 29 famílias do assentamento. Esse conhecimento mais abrangente contribuiu para o entendimento da realidade em que vivem os jovens rurais do assentamento.

Para a coleta de informações sobre os jovens, a técnica utilizada foi de entrevista semiestruturada, seguindo-se um roteiro de perguntas, demonstradas no Apêndice I, que permitiam respostas abertas e descritivas, visando conhecer como os jovens entendem a sua posição junto à família, à propriedade e à comunidade, quais seriam os fatores limitantes ao seu desenvolvimento e quais as perspectivas com relação ao seu plano de futuro.
No Brasil, a Política Nacional da Juventude delimita uma faixa etária para a juventude entre 15 e 29 anos, período compreendido entre a puberdade e a idade adulta (BRASIL, 2006).

As entrevistas foram realizadas com jovens entre 15 e 28 anos, individualmente, sem a participação de nenhum membro da família, para que não houvesse qualquer tipo de interferência sobre as respostas. No assentamento vivem 27 jovens que estão nesta faixa etária, sendo 18 homens e 9 mulheres, conforme observado na Tabela 1, que moram com os pais nas propriedades. Foi utilizada a abordagem qualitativa de pesquisa. Segundo Godoy (1995), este método possibilita estudar os fenômenos que envolvem os seres humanos e suas relações sociais estabelecidas em diversos ambientes. Para isto, o pesquisador vai a campo captar o fenômeno em estudo a partir da percepção das pessoas, sempre considerando o que o entrevistado pensa sobre as situações indagadas.

\section{Resultados e discussões}

\subsection{Caracterização do assentamento Florestan Fernandes}

$\mathrm{O}$ assentamento Florestan Fernandes, distante $5 \mathrm{~km}$ da cidade de Florestópolis (PR), tem área de 529,01 hectares, sobre os quais foram assentadas 29 famílias mobilizadas pelo MST. A área média explorada por família é de 14,38 hectares. O restante da área, 112,29 hectares, é de domínio comunitário e está composta pela reserva legal, área de preservação permanente, estradas e centro comunitário (INCRA, 2008).

Tabela 1. População jovem do Assentamento Florestan Fernandes, entre 15 e 28 anos

\begin{tabular}{lcc}
\hline Faixa etária & Total de homens & Total de mulheres \\
\hline 15 a 18 anos & 7 & 2 \\
19 a 22 anos & 6 & 3 \\
23 a 28 anos & 5 & 4 \\
\hline
\end{tabular}

Fonte: Pesquisa de campo, 2010. 
Os sistemas de produção desenvolvidos pelas famílias têm como principais atividades a bovinocultura de leite e a criação de bicho da seda que são comercializadas diretamente com as empresas integradas. A produção de feijão, milho, mandioca e pequenos animais é desenvolvida para consumo próprio. A bovinocultura de leite se destaca como a atividade presente em $93 \%$ das propriedades.

\subsection{A participação do jovem no assentamento}

Os jovens do assentamento foram questionados sobre a participação nas decisões referentes às atividades desenvolvidas na propriedade. Dentre estes jovens, 70,3\% relataram não haver qualquer tipo de participação, acatando apenas o que os pais decidem fazer. Os outros $29,7 \%$ afirmam que os pais solicitam opiniões sobre determinados investimentos ou serviços, mas que a decisão final é dos pais.

O mesmo questionamento sobre a participação nas discussões de assuntos gerais da comunidade também mostra que $77,7 \%$ não são convidados a participar das reuniões ou entendem que os assuntos tratados são apenas para os pais. Os 22,3\% restantes vão às reuniões quando os pais não podem participar ou quando o assunto, mais abrangente, os envolvem.

Os jovens têm propostas de melhorias na propriedade e demonstram que podem contribuir para o desenvolvimento das atividades. Para conhecer estas propostas, foi perguntado a eles o que fariam se fossem os proprietários dos lotes. A maioria dos jovens, $77,8 \%$, respondeu que iriam trabalhar somente com a atividade de bovinocultura de leite, melhorando a produtividade por meio da reforma e manejo de pastagens e melhoria da genética do rebanho, por entenderem que esta atividade é a que está viabilizando as propriedades em virtude de proporcionar renda regular obtida pela venda do leite, pela venda de bezerros e crescimento do número de animais através da evolução do rebanho. Aqueles que desenvolvem a criação do bicho-da-seda como parte do sistema produtivo disseram que gosta- riam de parar com a atividade por ser muito trabalhosa e pela necessidade de tratos no período da madrugada, ficando apenas com a atividade leiteira. Os outros $22,2 \%$ responderam que venderiam a propriedade ou que não tinham uma opinião formada sobre o assunto.

Quando questionados se conversavam com os pais sobre estas propostas, $89 \%$ disseram que não. Diversas foram as respostas: "Porque meu pai não me ouviria"; "São apenas eles que decidem"; "Acho que ele não faria estas coisas".

Esta situação encontrada no assentamento Florestan Fernandes demonstra o que Castro (2009) afirma, que ser jovem carrega a marca da pouca confiabilidade na hierarquia das relações familiares, ainda que assuma posição de destaque nos discursos sobre a continuidade dos assentamentos. Essa autoridade patriarcal cria mecanismos de vigilância e controle sobre os jovens através das relações familiares e demais redes sociais.

O sentimento da necessidade de autonomia pelos jovens do assentamento em relação aos pais é percebido. A solução para este anseio, de acordo com Brumer (2006), requer mudanças nas relações familiares, através da participação maior de todos os trabalhadores familiares no processo de tomada de decisões e de um maior espaço para a atuação dos jovens.

\subsection{Relação do jovem com o trabalho}

Somente 18,5\% trabalham fora do assentamento, mas, quando podem, realizam eventuais serviços no lote. Os jovens restantes, $81,5 \%$, trabalham todos os dias na propriedade, manejando e alimentando o rebanho, ordenhando vacas, preparando capineiras, manejando a criação do bicho-da-seda, além de outros trabalhos, sendo alguns apenas por meio período, por estarem frequentando a escola. Destes, $72,7 \%$ não têm restrição em realizar os trabalhos, sendo que vários manifestaram até "gosto" pelo serviço; 27,3\% disseram não gostar de realizar certas tarefas, mas faziam pela necessidade da propriedade. Esta manifestação negativa foi observada principal- 
mente dentre os jovens que desenvolvem a atividade de criação do bicho-da-seda.

Referente ao questionamento sobre algum pagamento ou salário recebido pelos trabalhos desenvolvidos na propriedade, apenas um jovem comentou receber uma quantia mensal, tratando-se, na visão dele, mais como uma mesada do que propriamente um salário, devido ao baixo valor. Os demais não recebem um valor fixo que possam se planejar para aquisição de algum bem pessoal. Eventualmente, quando precisam comprar alguma mercadoria, precisam solicitar dinheiro aos pais. Quando surge uma oportunidade, alguns jovens trabalham em propriedades vizinhas, como diaristas.

Para os jovens do assentamento, esta é uma situação muito frustrante, uma vez que é manifestado o desejo de acesso a uma renda própria, em que eles possam custear as suas necessidades particulares sem recorrer aos pais.

\subsection{O jovem e a perspectiva de futuro}

Explorando a perspectiva do jovem com relação ao seu futuro, a pesquisa mostrou que alguns têm certo dilema em relação ao "ficar na propriedade" e ao "sair da propriedade". Foram identificados três tipos de perspectivas, apresentados a seguir:

1. Jovem que quer sair: este grupo é formado por $22,2 \%$ dos jovens, sendo metade de cada gênero. A razão para este desejo se deve ao fato de não se identificarem com a vida de agricultor, almejando trabalhar em outras profissões, pretendendo ingressar em faculdades ou realizar cursos técnicos. Este grupo heterogêneo apresenta realidades distintas, com jovens que vivem em propriedades que apresentam boa rentabilidade e outros que vivem em condições financeiras limitadas.

2. Jovem que necessita sair, mas preferia ficar: representados por $44,4 \%$ do total, estes jovens gostam de trabalhar com atividades rurais e viver na comunidade, mas relatam que, em virtude da dificuldade financeira da família, desejam buscar oportunidades de renda própria no ambiente urbano. Houve também reclamações sobre a dificuldade de acesso a políticas públicas, como a linha de crédito Pronaf Jovem, que vincula a liberação de recursos a alguma formação técnica agropecuária, demonstrando o quanto as políticas e programas governamentais ainda reiteram o caráter da autoridade patriarcal e não favorece uma perspectiva de futuro, com permanência nas atividades agrícolas para os "jovens rurais". Da mesma forma que o primeiro grupo, alguns pretendem cursar uma faculdade, um curso técnico ou apenas trabalhar em alguma empresa, sem necessariamente ser do ramo agropecuário.

3. Jovem que quer ficar: a situação deste grupo de jovens formado por $33,4 \%$ do total apresenta realidade econômica mais favorável, que tem melhor condição de vida que a do segundo grupo. São jovens que, além destas vantagens, identificam-se com a agropecuária e com a vida na comunidade. Têm interesse em melhorar o conhecimento referente às atividades desenvolvidas por meio de cursos técnicos, faculdades ou treinamentos e são incentivados pelos pais a permanecerem na propriedade, mesmo ainda não recebendo remuneração mensal no trabalho desenvolvido, mas acreditando que no futuro esta divisão seja mais racional.

Brumer (2006) apontava que o acesso à renda própria também era um dos motivos para justificar a migração de jovens rurais. Isso porque, no ambiente familiar rural, na maioria das vezes, os recursos não são divididos e são controlados pelo pai. O trabalho assalariado no meio urbano passa, então, a representar uma boa opção para a conquista de uma renda própria pelos jovens rurais.

Contudo, Castro (2009) destaca que não se deve tratar a questão como apartada das dificulda- 
des enfrentadas pelos pequenos produtores familiares. Isto é, os problemas enfrentados pelos jovens são, antes de tudo, problemas enfrentados pela pequena produção familiar e suas muitas formas de reprodução, como as difíceis condições de vida e produção. Neste contexto, algumas dificuldades atingem de forma mais direta os jovens rurais.

\subsection{Lazer e cultura}

As opções de cultura e lazer no assentamento se limitam a: jogo de futebol em área de pastagem, visita a uma represa localizada em uma propriedade da comunidade, assistir televisão, eventuais visitas à cidade e a utilização por alguns jovens de computador e internet ${ }^{3}$.

Os jovens entrevistados anseiam por um espaço no assentamento sobre o qual possam desenvolver a cultura e o lazer. Segundo eles, este espaço deveria ser um local de ponto de encontro sobre o qual existiria um campo de futebol, quadra de vôlei de areia, local para apresentações de músicas, promoção de eventos, peças de teatro, biblioteca, computadores com internet, favorecendo a socialização dos jovens e das famílias, além da possibilidade de trazer amigos da cidade para participar da comunidade.

No depoimento dos jovens, ocorrem afirmações de que a comunidade não é unida. Mas, com a implantação de um local para o desenvolvimento da cultura e lazer, esta situação poderia ser amenizada, elevando a participação das famílias e estreitando os laços de amizade e confiança.

O assentamento tem uma área destinada ao Centro Comunitário, com aproximadamente 6,0 ha, constituído por uma igreja católica, e um grande barracão que é utilizado apenas pelos adultos para a realização de reuniões e algum evento festivo ou religioso.

Diferente do relatado por Carneiro (1998), os jovens do assentamento estudado não associaram o interesse por sair do campo à falta de opções de lazer, porém, manifestaram que tais opções melhorariam muito suas relações sociais.

3 Articulado pela Emater local, foi instalado neste assentamento, em 2009, o acesso à internet via rádio. Dez famílias têm computadores e se conectam à rede.
Stédile (2001) comenta que o jovem rural sonha em ver, no assentamento, opções de lazer existentes na cidade, o que é uma ilusão, porque na cidade existem muitas alternativas de lazer somente para quem tem dinheiro; para a juventude pobre da periferia, as alternativas de lazer também inexistem. No entanto, cada assentamento deve ter criatividade para resolver este desejo.

\subsection{A luta pela terra}

Conforme Castro (2009), o Plano Nacional de Reforma Agrária não se articula entre os problemas estruturais enfrentados pelas famílias assentadas e os processos de sucessão e expansão das atividades agropecuárias pelas novas gerações, indicando às novas gerações que muitos dos que têm intenção de permanecer no campo terão que iniciar nova luta por acesso às terras.

Considerando-se o fato de que os lotes ou as propriedades do assentamento têm uma área limitada que proporciona uma pequena rentabilidade para reprodução das famílias, e em muitos casos impossibilitando ou dificultando a divisão entre irmãos, o jovem foi provocado, nesta pesquisa, a indagar sobre a possibilidade de participação em novos acampamentos para a conquista de um lote no sentido de dar continuidade à vida de agricultor.

Apesar de a maioria ter manifestado o desejo em continuar vivendo no meio rural, a experiência de alguns que vivenciaram com os pais a difícil realidade da luta pela terra e o próprio desestímulo da família em virtude desta mesma dificuldade, $88 \%$ dos jovens afirmaram não ter interesse em participar do Programa de Reforma Agrária por meio do processo de acampamentos e ocupações de propriedades, preferindo buscar outras oportunidades de trabalho ou viverem com os pais.

\section{Conclusões}

A partir da realidade que foi apresentada, pode-se concluir que a maioria dos jovens deste 
assentamento tem o desejo de permanecer e trabalhar com os pais, mas a limitada rentabilidade econômica das propriedades e a falta de renda própria, além da incerteza quanto à garantia de espaço para se instalar na área quando constituir sua própria família, são os principais fatores de desestímulo na sucessão do empreendimento, fazendo com que o jovem sinta a necessidade de abandonar o meio rural.

Não é fornecida ao jovem a oportunidade de participação nas discussões referentes aos problemas e soluções tanto da propriedade quanto da comunidade, sendo vistos apenas como força de trabalho local. Esta não valorização aparenta uma falsa imagem de que o jovem não tem interesse pelo desenvolvimento do assentamento.

A educação é vista pelos jovens como uma possibilidade de melhoria de vida, seja no meio rural ou urbano, por meio de capacitação para aprimorar a profissão de agricultor ou na formação para outra atividade profissional. É preciso respeitar a opção do jovem sobre a profissão que gostaria de exercer e possibilitar condições para que possa estudar.

A vontade de promover espaços para a cultura e lazer no assentamento é uma necessidade demandada pelos jovens e vista como elemento de maior socialização das famílias e bem-estar na comunidade.

A área dos lotes do assentamento tem potencial para a reprodução de até duas famílias. Em virtude desta limitação, seria inviável a divisão deste mesmo lote entre mais filhos que pretendam continuar na atividade agropecuária e constituir a sua própria família. É importante a discussão de políticas públicas para aqueles jovens que permanecerão no lote com os pais, facilitando o acesso ao crédito para suas atividades, além de privilegiar o acesso à terra, por meio do Programa Nacional de Reforma Agrária, aos outros filhos que demonstram interesse na profissão de agricultor, aproveitando a experiência e a vocação que eles têm.

\section{Considerações finais}

Ao se discutir o futuro dos assentamentos rurais e da agricultura familiar, há que se conhecer a realidade da juventude rural de hoje, uma vez que, teoricamente, esses jovens estariam sucedendo seus pais na exploração do lote. Para isto, é importante conhecer o ambiente em que os jovens estão inseridos, suas angústias, necessidades e perspectivas.

Neste estudo, foi possível identificar que a maioria dos jovens manifesta a vontade de continuar vivendo no assentamento, mas, em virtude da limitação da renda obtida na propriedade, muitos deles sentem a necessidade de abandonar o assentamento em busca de sua independência financeira deixando para trás uma população rural envelhecida, o que não confirma a hipótese da pesquisa deste artigo, que considerava que o desejo dos jovens de abandonar o assentamento se devia ao fato de eles não estarem mais identificados com a vida no campo, sendo atraídos pela diversidade de opções oferecidas pelo meio urbano.

Não é um desejo do jovem querer sair do assentamento, mas uma necessidade. Mesmo assim, esta necessidade se torna preocupante, uma vez que a maioria dos jovens entrevistados não tem capacitação profissional para enfrentar o exigente mercado de trabalho do meio urbano. Por outro lado, aqueles que podem permanecer no campo estão limitados aos conhecimentos práticos do trabalho rural que executam e não estão sendo capacitados de uma forma mais profissional para exercer a profissão de produtor rural.

Este cenário se deve, em parte, por alguns pais que não estimulam os filhos a seguir a vida no meio rural e pela maioria das entidades governamentais e não governamentais que não dedicam a merecida atenção para a preocupação em criar mecanismos que possam possibilitar a permanência da juventude no meio rural. 
O abandono do meio rural pelo jovem pode ameaçar a própria reforma agrária, principalmente nestes assentamentos que foram criados e que demonstram a incapacidade de manter a juventude no campo, interrompendo o processo sucessório e colocando em risco a continuidade e a existência do assentamento.

\section{Referências bibliográficas}

ABRAMO, H. W. e BRANCO, P. P. M. (Org.). Retratos da Juventude Brasileira: Análises de uma Pesquisa Nacional. Instituto Cidadania, Editora Fundação Perseu Abramo, São Paulo, 2005.

ABRAMOVAY, R. et al. (Coord.). Juventude e agricultura familiar: desafios dos novos padrões sucessórios. Brasília: Unesco, 1998.

BADALOTTI, R. M., RENK, A., BERTONCELLO, A., ROSSY, A. M., AMARAL, E. e DALLAZEN, R. Reprodução Social da Agricultura Familiar e Juventude Rural no Oeste Catarinense. VII RAM - UFRGS, Porto Alegre, Brasil, 2007 - GT 01: Antropologia Económica y Ecológica. Coordenação: Alejandro Balazote (UBA/ UNLu, Argentina) e Maria José Reis (UFSC, Brasil).

BAMAT, T. e IENO NETO, G. (orgs.) Qualidade de vida e reforma agrária na Paraíba. João Pessoa, UNITRABALHO/ UFPB, 1998.

BRASIL. Guia de políticas públicas de juventude. Brasília: Secretaria-Geral da Presidência da República, 2006.

BRASIL. Lei 11.326. Estabelece as diretrizes para a formulação da Política Nacional da Agricultura Familiar e Empreendimentos Familiares Rurais. 24/06/2006.

BRASIL. Ministério do Desenvolvimento Agrário Agricultura familiar no Brasil e o Censo Agropecuário 2006. Disponível em: http://portal.mda.gov.br/portal/ saf/arquivos/view/arquivos-destaque/censo_2006.pdf. Acessado em 04/05/2010.

BRUMER, A. Gênero e Agricultura; a situação da mulher na agricultura no Rio Grande do Sul. Revista Estudos Feministas, Florianópolis, v. 12, n, p. 205-227, 2004.

A. A problemática dos jovens rurais na pósmodernidade. In: VII Congresso Latino Americano de Sociologia Rural, 2006. Quito (Equador) Anais, 2006.

CAMARANO, A. A. e ABRAMOVAY, R. Êxodo rural, envelhecimento e masculinização no Brasil: Panorama dos últimos cinqüenta anos. Trabalho apresentado no
21ํㅡㄹ Congresso da Associação Nacional de Pesquisa e pós graduação em Ciências sociais. Caxambu, SP, 1997.

CAMPOLIN, A. I. Educação Rural: Um debate necessário. ADM - Artigo de divulgação na Mídia, Embrapa Pantanal, Corumbá-MS, n. 87, p.1-3. nov. 2005.

CARNEIRO, M. J. Ruralidade: novas identidades em construção. Estudos Sociedade e Agricultura, n. 11, Rio de Janeiro: CPDA/UFRRJ, 1998.

M. J. Juventude rural: projetos e valores. In.: ABRAMO, H. e BRANCO, P. M. D. (Orgs.). Retratos da juventude brasileira: análises de uma pesquisa nacional. São Paulo: Instituto Cidadania/Perseu Abramo, 2005.

CARVALHO, A., SOARES Jr, D., LIRA, M. P., FIGUEIREDO, R., LLANILLO, R. F. e CARNEIRO, S. L. Sistemas de Produção Familiares do Norte do Paraná. Rede de Referência, IAPAR e EMATER. Convênio Projeto Paraná 12 Meses e PRONAF. Londrina-Pr, 56p. 2001.

CASTRO, E. G. Assentamento entre o rural e o urbano. In. CARNEIRO, M. J. (Orgs.). Campo Aberto - O rural no Estado do Rio de Janeiro. Rio de Janeiro: Contra Capa livraria ltda., 1998.

E. G. Juventude rural no Brasil: processos de exclusão e a construção de um ator político. Rev. latinoam. cienc. soc. Niñez. juv, Manizales, v. 7, n. 1, jan. 2009. Disponível em: < http://www.scielo.org.co/scielo. php? script $=$ sci_arttext\&pid $=$ S1692-715X2009000100008 \&lng $=$ en\&nrm $=i$ iso $>$. Acessado em 11 jul. 2010.

DURSTON, J. A juventude rural no Brasil e no México: reduzindo a invisibilidade. Ideias \& Debate. Brasília: Instituto Teotônio Vilela, n. 27, 1999.

EMATER. Instituto Paranaense de Assistência Técnica e Extensão Rural. Plano de trabalho integrado para o ano de 2008 e relatório de atividades do ano de 2007 do município de Florestópolis-Pr. Florestópolis: Emater \{s.n.\}, 2008.

GOOGLE EARTH. Localização do assentamento Florestan Fernandes - Florestópolis/PR 21 julho. 2010.

GODOY, A. S. Pesquisa Qualitativa: Tipos Fundamentais. ERA - Revista de Administração de Empresas. São Paulo, v. 35, n. 35, p. 21-29. 1995.

INCRA. Instituto Nacional de Colonização e Reforma Agrária. Superintendência Regional do Paraná -SR (09). Relatório do P.A. Florestan Fernandes - município de Florestópolis-PR. Curitiba-PR, 2008.

LOURENZANI, W. L. Capacitação gerencial de agricultores familiares: uma proposta metodológica de extensão rural. In: Organizações Rurais e Agroindústrias. Revista de Administração da UFLA, Lavras-MG, v. 8, n. 3, set./dez. 2006. 
PAULILO, M. I. S. Trabalho familiar: uma categoria esquecida de análise. Estudos Feministas, Florianópolis, v. 12, n. 1, p. 229-52, 2004.

PEREIRA, J. Jr. A fixação do jovem no campo: Um desafio para os sindicatos dos trabalhadores rurais. Disponível em: <http://www.jpjconsultoria.com.br/index.php >. Acesso em: 15 abr. 2010.

REUBEN, W. La juventud rural en América Latina y em Caribe. San José: Instituto Interamericano de Cooperación para la Agricultura (IICA), 1990.
ROCHA, H. F. Análise e mapeamento da implantação de assentamentos rurais e da luta pela terra no Brasil entre 1985 - 2008. Presidente Prudente, 2009. Trabalho de monografia - Faculdade de Ciências e Tecnologia, Universidade Estadual Paulista, 2009.

SILVESTRO, M. L. et al. Os impasses sociais da sucessão hereditária na agricultura familiar. Florianópolis: EPAGRI. 2001.

STÉDILE, J. P. Vida e trabalho nos assentamentos rurais. CD ROM produzido pelo Movimento dos Trabalhadores Rurais Sem Terra. 2001. 


\section{Anexo 1. Questionário de Tipologia}

\section{QUESTIONÁRIO DE TIPOLOGIA}

\begin{tabular}{|c|c|c|c|c|c|c|}
\hline $\begin{array}{l}\text { Data da } \\
\text { entrevista }\end{array}$ & Agricultor(a) & & & & Código & \\
\hline Município & Florestópolis & $\begin{array}{l}\text { Bairro/ } \\
\text { comunidade }\end{array}$ & & $\begin{array}{l}\text { Telefone } \mathrm{p} / \\
\text { contato }\end{array}$ & & \\
\hline $\begin{array}{l}\text { Nome da } \\
\text { propriedade }\end{array}$ & & & Técnico & & & - \\
\hline
\end{tabular}

1. Características da família do produtor

\begin{tabular}{|l|l|l|l|l|l|l|l|l|l|}
\hline \multirow{2}{*}{ Nome } & Sexo & \multirow{2}{*}{$\begin{array}{c}\text { Data de } \\
\text { nascimento }\end{array}$} & $\begin{array}{c}\text { Condição na uni- } \\
\text { dade domiciliar }\end{array}$ & $\begin{array}{c}\text { Local de } \\
\text { morada }\end{array}$ & \multicolumn{2}{|c|}{ Instrução } & \multirow{2}{*}{$\begin{array}{c}\text { Situação } \\
\text { ocupac. }\end{array}$} & \multicolumn{2}{c|}{ Outras fontes renda } \\
\hline
\end{tabular}

2. Mão-de-obra extra-familiar (temporária e permanente)

\begin{tabular}{|l|l|l|r|}
\hline Atividade/operação & $\begin{array}{c}\text { No de } \\
\text { pessoas }\end{array}$ & № de dias & DH \\
\hline & & & - \\
\hline & & & - \\
\hline & & & - \\
\hline & & & - \\
\hline & & & - \\
\hline & & & \\
\hline
\end{tabular}


है

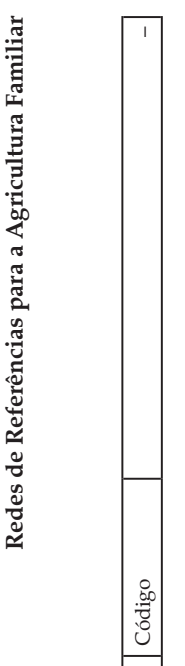

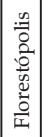

율

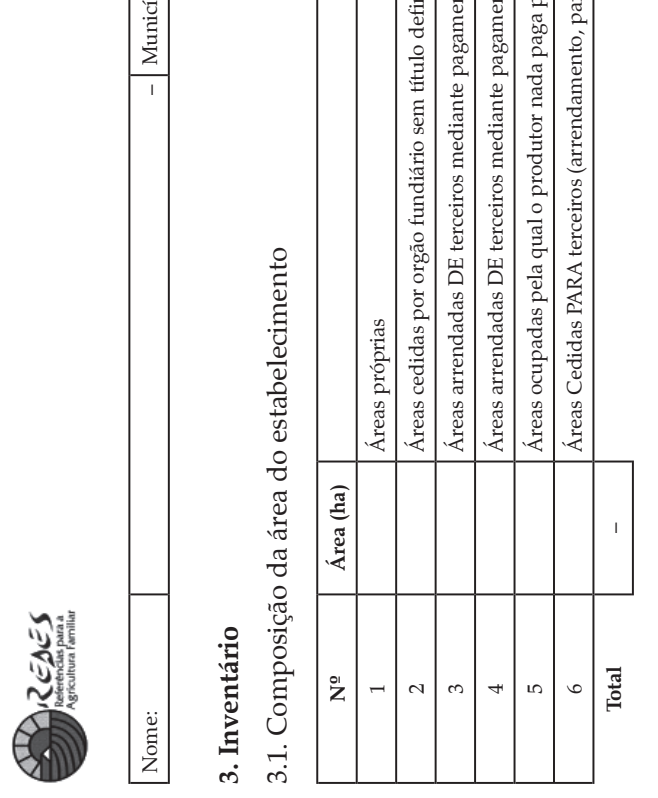

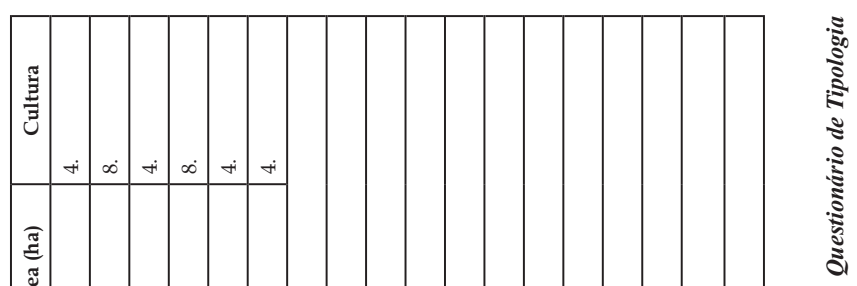

莺

8
0
0
0
0

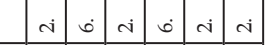

ฮ્శ

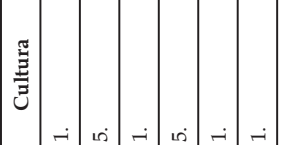

氕

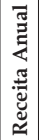

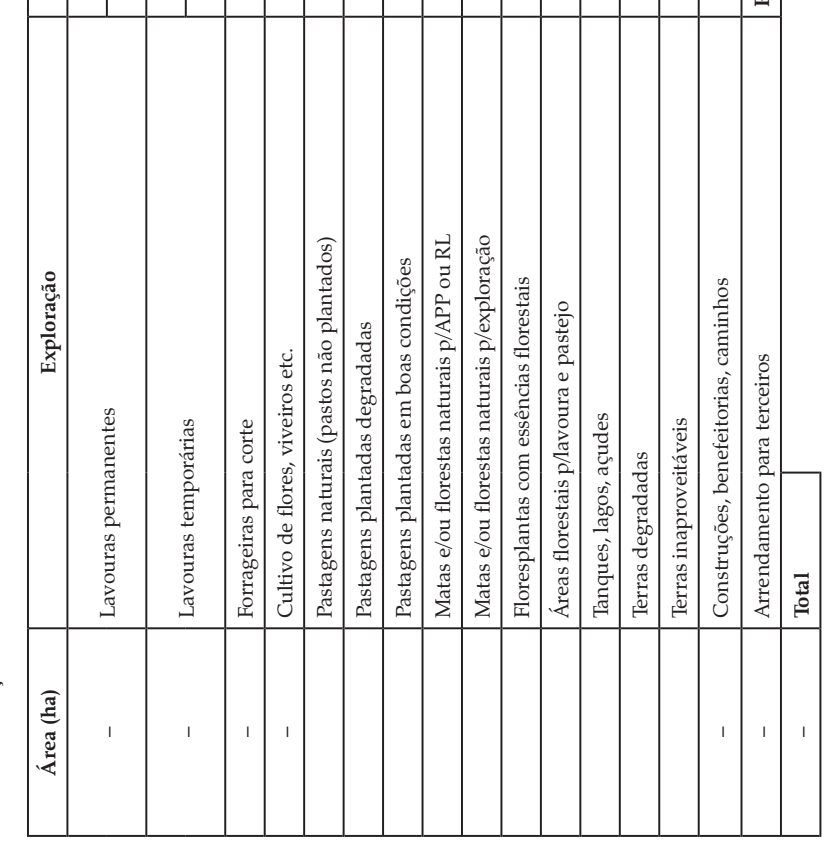

RESR, Piracicaba-SP, Vol. 51, № 3, p. 415-432, Jul/Set 2013 - Impressa em Outubro de 2013 


\section{Composição anual das receitas}

4.1. Receita Bruta da Produção Realizada na Última Safra (vegetal/animal)

\begin{tabular}{|c|c|c|c|c|c|c|c|c|c|}
\hline \multirow[b]{2}{*}{ Código } & \multirow[b]{2}{*}{ Produto } & \multirow[b]{2}{*}{ Unidade } & \multirow[b]{2}{*}{ Quantidade } & \multirow[b]{2}{*}{ Preço } & \multirow[b]{2}{*}{ Valor (R\$) } & \multirow[b]{2}{*}{$\%$} & \multicolumn{3}{|c|}{ Destino(s) } \\
\hline & & & & & & & Código & Código & Código \\
\hline & - & - & & & - & & & & \\
\hline & - & - & & & - & & & & \\
\hline & - & - & & & - & & & & \\
\hline & - & - & & & - & & & & \\
\hline & - & - & & & - & & & & \\
\hline & - & - & & & - & & & & \\
\hline & - & - & & & - & & & & \\
\hline & - & - & & & - & & & & \\
\hline & - & - & & & - & & & & \\
\hline & - & - & & & - & & & & \\
\hline & - & - & & & - & & & & \\
\hline & - & - & & & - & & & & \\
\hline
\end{tabular}

4.2. Outras Rendas Anuais

\begin{tabular}{|c|c|c|}
\hline Descrição & Valor (R\$) & \\
\hline Outras fontes de rendimento - NÂO! & 0,00 & \\
\hline Arrendamentos - NÂO! & 0,00 & \\
\hline Outras (total) & & OR/RBT ( $\%)$ \\
\hline TOTAL & 0,00 & \#DIV/0! \\
\hline
\end{tabular}

4.3. Renda Vruta Total

CLASSIFICAÇÃO 


\section{Qualidade de vida}

5.1. Moradia (somente a moradia principal, dentro ou fora do estabelecimento rural)

\begin{tabular}{|l|l|l|l|}
\hline \multicolumn{2}{|l|}{ Área $\left(\mathrm{m}^{2}\right)$} & & Ano de construção \\
\hline \multicolumn{2}{|l|}{ Material predominante } & \multicolumn{2}{l|}{ Estado de conservação } \\
\hline & Alvenaria, tijolo, material, concreto, cimento & Excelente (novo ou em estado de novo) \\
\hline & Madeira & & Bom (com pouco desgaste e totalmente utilizável) \\
\hline & Metálico & & Regular (desgastado, mas ainda utilizável) \\
\hline & Misto (madeira/alvenaria) & & Razoável (com alguns problemas) \\
\hline & & Sofrivel (com muitos problemas) \\
\cline { 2 - 3 } & & Péssimo (não-utilizável) \\
\cline { 2 - 3 }
\end{tabular}

5.2. Abastecimento d'água utilizado na casa onde reside a familia?

\begin{tabular}{|l|l|l|l|}
\hline & Rede pública & Mina d'água, fonte, córrego, rio, açude - Op. manual \\
\hline & Poço artesiano com bomba elétrica & Mina d'água, fonte, córrego, rio, açude - Op. mecânica \\
\hline & Poço comum com bomba elétrica & Outros \\
\hline & Poço comum com operação manual & & \\
\cline { 1 - 2 } & &
\end{tabular}

5.3. Qual o tipo de sanitário utilizado na casa onde reside a família?

\begin{tabular}{|l|l|l|l|}
\hline & Sanitário dentro da residência & No mato, a céu aberto \\
\hline & Sanitário externo, anexo a residência & & Outros \\
\hline & Sanitário externo a residência - tipo "casinha" & & \\
\cline { 1 - 2 } & &
\end{tabular}

5.4. Qual o destino dos dejetos (esgoto) da casa onde reside a família?

\begin{tabular}{|l|l|l|l|}
\hline & Rede pública & Encanado/jogado/canalizado para rio/córrego/ribeirão \\
\hline & Fossa séptica - tanque fechado e impermeável & & Outros \\
\hline & Fossa seca ou negra - dejetos lançados diretamente & & \multicolumn{2}{|l}{} \\
\cline { 1 - 2 } &
\end{tabular}

5.5. Qual a origem da iluminação utilizada na casa onde reside a família?

\begin{tabular}{|l|l|l|l|}
\hline & Luz elétrica - REde pública & Lampião a gá, querosene \\
\hline & Luz elétrica - gerador próprio & Outros \\
\hline
\end{tabular}

5.6. Qual a destinação ao lixo comum produzido na propriedade?

\begin{tabular}{|l|l|l|l|}
\hline & Recicla e destina para coleta pública & Queima \\
\hline & Coleta pública & Joga em terreno/rio \\
\hline & Enterra & & Outros \\
\hline
\end{tabular}

5.7. Qual a destinação dada ao lixo orgânico produzido na propriedade?

\begin{tabular}{|l|l|l|}
\hline & Recicla (enterra na horta, faz compostagem etc.) & Queima \\
\hline & Destina para a coleta pública & Joga em terreno/rio \\
\hline & Enterra & Outros \\
\hline
\end{tabular}

5.8. Como se dá o acesso da família aos seguintes serviços?

\begin{tabular}{|c|c|c|c|c|c|c|c|}
\hline & \multirow{2}{*}{ Sem acesso } & \multicolumn{3}{|c|}{ Natureza do serviço utilizado } & \multicolumn{3}{|c|}{ Localização do serviço utilizado } \\
\hline & & Público & Privado & Público/Privado & Comunidade & Sede município & Outros locais \\
\hline \multicolumn{8}{|l|}{ Atendimento médio } \\
\hline \multicolumn{8}{|c|}{ Atendimento odontológico } \\
\hline \multicolumn{8}{|l|}{ Educação } \\
\hline Transporte público & & & & & & & \\
\hline
\end{tabular}


430 - A Juventude Rural do Assentamento Florestan Fernandes no Município de Florestópolis (PR)

5.9. Quais os meios de transporte de que a família dispões?

\begin{tabular}{|l|l|l|l|}
\hline & Mais de um veículo (passeio/transp. de mercadorias) & Bicicleta \\
\hline & Um veículo (passeio ou transp. de mercadorias) & & Carroça / Cavalo \\
\hline & Motos e assemelhados & & Sem meio de locomoção próprio \\
\hline
\end{tabular}

5.10. Quais os equipamentos a família dispões?

\begin{tabular}{|l|l|l|l|}
\hline & Fogão à gás & Aparelho de som \\
\hline & Fogão à lenha & Computador \\
\hline & Geladeira & Televisão \\
\hline & Freezer & Telefone fixo \\
\hline & Batedeira & Telefone celular \\
\hline & Liquidificador & Outros \\
\hline & Rádio & Outros \\
\hline
\end{tabular}

\subsection{Atividades de lazer}

\begin{tabular}{|l|l|l|l|}
\hline Quais os dias semanais de descanso da família? & \multicolumn{2}{|l|}{} & \\
\hline Quais as três principais atividades destes dias? & & \\
\hline Qual a periodicidade de descanso prolongado da família? & & Uma vez a cada 3 anos \\
\hline & Uma vez por ano - 30 dias de descanso & & Esporadicamente, períodos curtos para passeio \\
\hline & Uma vez por ano - pelo menos 7 dias de descanso & Não tira férias \\
\hline & Uma vez a cada 2 anos & Número médio de dias/férias \\
\hline & Qual foi o último ano em que a família tirou férias? & & \\
\hline
\end{tabular}

5.12. Integração social

\begin{tabular}{|c|c|c|c|c|c|c|}
\hline \multirow{2}{*}{ O produtor participa / frequenta } & \multirow{2}{*}{ Sim } & \multirow{2}{*}{ Não } & \multirow{2}{*}{ Qual(is)? } & \multicolumn{3}{|c|}{ Exerce alguma função? } \\
\hline & & & & Sim & Não & Qual? \\
\hline \multicolumn{7}{|l|}{ Igreja } \\
\hline \multicolumn{7}{|l|}{ Cooperativa } \\
\hline \multicolumn{7}{|l|}{ Sindicato } \\
\hline \multicolumn{7}{|l|}{ Associação de produtores } \\
\hline \multicolumn{7}{|l|}{ Associação comunitária } \\
\hline \multicolumn{7}{|l|}{ Conselhos municipais } \\
\hline Outras entidades & & & & & & \\
\hline
\end{tabular}

\section{Sucessão familiar}

Qual é a expectativa para o futuro de seus filhos? (Somente aquele(s) que ainda está(ão) na propriedade)

\begin{tabular}{|l|l|l|l|}
\hline & Continuar trabalhando na propriedade em atividades agrícolas & & Deixar a propriedade e continuar no campo \\
\hline & Continuar morando na prop. e trabalhar fora dela em ativ. agrícola & & Deixar a propriedade e ir para a cidade \\
\hline & Continuar moran. na prop. e trabalhar fora dela em ativ. não agric. & & Filhos já estão desligados das atividades da propriedade \\
\hline & Outras (descreva) & & \\
\hline
\end{tabular}




\section{Apêndice I. Roteiro de perguntas para os jovens rurais do Assentamento Florestan Fernandes}

1. Identificação:

( ) Masculino

( ) Feminino

Data de nascimento:

Escolaridade:

Como é constituída a sua família?

2. Quais os bens materiais que existe na sua propriedade? ( residência, veículos, equipamentos, internet, benfeitorias, eletrodomésticos)

3. Quais atividades são desenvolvidas na propriedade? Que outras fontes de renda possuem fora da propriedade?

4. Você participa das decisões sobre as atividades desenvolvidas na propriedade? Como?

5. Você participa das discussões referente a comunidade/ assentamento, sobre assuntos que você acha que deveriam ser tratados. Se não - por quê?

6. Você ajuda com atividades ou trabalho na propriedade?

7. Se sim, é diário, semanal ou eventual? Que tipo de trabalho?

8. Você tem alguma restrição em desenvolver este serviço? Por quê?

9. Você recebe alguma forma de pagamento pelo seu trabalho? É suficiente?

10. Realiza alguma outra atividade fora da propriedade?

11. O que você faz no seu tempo livre?

12. Você se relaciona com os outros jovens do assentamento? Como?

13. Quais são os objetivos/planos pessoais para o seu futuro e como pretende alcançá-los?

14. Você gosta de viver no meio rural/assentamento? Por quê?

15. Você gostaria de continuar morando no meio rural/assentamento e trabalhando com agropecuária?

16. Se a propriedade fosse sua, quais seriam suas atitudes em relação a propriedade? Por quê? Você já falou isto com o seu pai?

17. Como você acha que deveria ser a comunidade e ou a propriedade em que você mora, para que fossem melhores de se viver? 